\title{
Change in serum proteome during allogeneic hematopoietic stem cell transplantation and clinical significance of serum C-reactive protein and haptoglobin
}

\author{
Joohyun Ryu ${ }^{1,5 *}$, Se Ryeon Lee ${ }^{2 *}$, Sung Goo Park ${ }^{1}$, \\ Sunghyun Kang ${ }^{1}$, Hyeoung-Joon $\mathrm{Kim}^{3,4,6}$ and \\ Byoung Chul Park ${ }^{1,6}$ \\ ${ }^{1}$ Medical Proteomics Research Center, KRIBB \\ Daejeon 305-333, Korea \\ ${ }^{2}$ Division of Hematology and Oncology \\ Department of Internal Medicine \\ Korea University Medical Center \\ Seoul 136-713, Korea \\ ${ }^{3}$ Blood and Marrow Transplant Center \\ ${ }^{4}$ Genome Research Center for Hematopoietic Disease \\ Chonnam National University Hwasun Hospital \\ Hwasun 519-809, Korea \\ ${ }^{5}$ Department of Biology \\ Kongju National University \\ Gongju 314-701, Korea \\ ${ }^{6}$ Corresponding authors: Tel, 82-42-860-4260; \\ Fax, 82-42-860-4593; E-mail, parkbc@ @ribb.re.kr (B.C.P) \\ Tel, 82-62-379-7637; Fax, 82-61-379-7628; \\ E-mail, hjoonk@ chonnam.ac.kr (H.J.K) \\ *These authors contributed equally to this work. \\ DOI 10.3858/emm.2010.42.9.065
}

Accepted 10 August 2010

Available Online 18 August 2010

Abbreviations: AA, aplastic anemia; ALL, acute lymphocytic leukemia; APPs, acute phase proteins; CML, chronic myeloid leukemia; CRP, C-reactive protein; CsA, cyclosporin A; $\mathrm{HLH}$, hemophagocytic lymphohistiocytosis; MDS, myelodysplastic syndrome; MMF, mycophenolate mofetil; MTX, methotrexate; NHL, non-Hodgkin lymphoma; SOS, sinusoidal obstruction syndrome

\begin{abstract}
Successful hematopoietic stem cell transplantation (HSCT) involves the restoration of hematopoietic function after engraftment, arising from the differentiation and proliferation of hematopoietic stem cells. Several factors could influence the course of allogeneic-HSCT (allo-HSCT). Therefore, knowledge of serum proteome changes during the allo-HSCT period might increase the efficacy of diagnosis and disease prevention efforts. This study conducted proteomic analyses to find proteins that were significantly altered in response
\end{abstract}

to allo-HSCT. Sera from five representative patients who underwent allo-HSCT were analyzed by 2-dimensional gel electrophoresis and liquid chromatography tandem mass spectrometry, and were measured on a weekly basis before and after allo-HSCT in additional 78 patients. Fourteen protein spots showing changes in expression were further examined, and most proteins were identified as acute phase proteins (APPs). Studies of 78 additional patients confirmed that C-reactive protein (CRP) and haptoglobin undergo expression changes during allo-HSCT and thus may have the potential to serve as representative markers of clinical events after allo-HSCT. Maximal CRP level affected the development of major transplant-related complications (MTCs) and other problems such as fever of unknown origin. Particularly, an increase in CRP level 21 days after allo-HSCT was found to be an independent risk factor for MTC. Maximal haptoglobin and haptoglobin level 14 days after allo-HSCT were predictive of relapses in underlying hematologic disease. Our results indicated that CRP and haptoglobin were significantly expressed during allo-HSCT, and suggest that their level can be monitored after allo-HSCT to assess the risks of early transplant-related complications and relapse.

Keywords: biological markers; C-reactive protein; haptoglobin; hematopoietic stem cell transplantation; proteomics; recurrence

\section{Introduction}

Successful HSCT or bone marrow transplantation involves the transplantation of new, functional immune systems after chemotherapy and radiotherapy. Allo-HSCT or bone marrow transplantation has been used successfully to treat hematopoietic malignancies, hematopoietic failure, autoimmune diseases, and genetic disorders (Copelan, 2006). The profiles of several serum proteins and peptides are altered during the processes of conditioning, stem cell infusion, and engraftment. Alterations in the serum proteome can reveal surrogate biomarkers, which can be assayed with relative ease to predict the outcomes and complications of allo-HSCT. These biomarkers, which include diffe- 
Table 1. Clinical characteristics of 78 patients who underwent allo-HSCT.

\begin{tabular}{|c|c|}
\hline Characteristics of the patients & Median (range) \\
\hline Duration of follow-up, median range (months) & $15.9(1.0-70.9)$ \\
\hline Patient age at transplantation, median range (years) & $37.2(16-62)$ \\
\hline Time to ANC $>500 / \mu$ l, median range (days) & $13.0(9-40)$ \\
\hline Time to platelet $>20,000 / \mu \mathrm{l}$, median range (days) & $16.2(7-89)$ \\
\hline \multirow[t]{2}{*}{ Time to platelet $>50,000 / \mu$ l, median range (days) } & $22.7(7-148)$ \\
\hline & Number (\%) \\
\hline $\operatorname{Sex}(M / F)$ & $40 / 38(51.3 / 48.7)$ \\
\hline \multicolumn{2}{|l|}{ Underlying disease } \\
\hline AML/ALL/Other leukemia* & $33 / 18 / 2(42.3 / 23.1 / 2.6)$ \\
\hline CML/MDS/AA/NHL/HLH & $5 / 5 / 11 / 3 / 1(6.4 / 6.4 / 14.1 / 3.8 / 1.3)$ \\
\hline \multicolumn{2}{|l|}{ Disease status at HSCT } \\
\hline Acute leukemia, CR1/CR2/NR & $33 / 17 / 3(62.3 / 32.1 / 5.6)$ \\
\hline CML, CP/AP/BC & $3 / 1 / 1(60.0 / 20.0 / 20.0)$ \\
\hline MDS, RA/RCMD/RAEB & $1 / 2 / 2(20.0 / 40.0 / 40.0)$ \\
\hline $\mathrm{AA}$, severe/very severe & $8 / 3(72.7 / 27.3)$ \\
\hline NHL, s/p auto-PBSCT/sensitive relapse & $1 / 2(33.3 / 66.7)$ \\
\hline $\mathrm{HLH}$ & $1(100)$ \\
\hline Graft type, sibling/untreated & $54 / 24(69.2 / 30.8)$ \\
\hline Stem cell source, BM/PBSC & $28 / 50(35.9 / 64.1)$ \\
\hline Sex compatibility, match/mismatch/data missing & $49 / 28 / 1(62.8 / 35.9 / 1.3)$ \\
\hline ABO compatibility, match/mismatch/data missing & $36 / 40 / 2(46.2 / 51.3 / 2.6)$ \\
\hline \multicolumn{2}{|l|}{ Conditioning regimen } \\
\hline Fludarabine-based/CTX-TBI/BU-CTX/CTX-ATG & $47 / 17 / 4 / 10(60.3 / 21.8 / 5.1 / 12.8)$ \\
\hline \multicolumn{2}{|l|}{ GVHD prophylaxis } \\
\hline CsA-based/Tacrolimus-based/data missing & $54 / 22 / 2(69.2 / 28.2 / 2.6)$ \\
\hline Engraftment, success/failure/data missing & $73 / 4 / 1(93.6 / 5.1 / 1.3)$ \\
\hline Acute GVHD, yes/no & $21 / 57(26.9 / 73.1)$ \\
\hline SOS, yes/no/data missing & $4 / 73 / 1(5.1 / 93.6 / 1.3)$ \\
\hline MTC (aGVHD + SOS) & $22 / 56(28.2 / 71.8)$ \\
\hline Acute other complication except MTC & $35 / 43(44.9 / 55.1)$ \\
\hline Relapse after allo-HSCT during follow-up & $24 / 54(30.8 / 69.2)$ \\
\hline
\end{tabular}

ANC, absolute neutrophil count; ALL, acute lymphocytic leukemia; CML, chronic myelogenous leukemia; MDS, myelodysplastic syndrome; AA, aplastic anemia; NHL, non-Hodgkin's lymphoma; HLH, hemophagocytic lymphohistiocytosis; HSCT, hematopoietic stem cell transplantation; CR2, complete remission after induction chemotherapy in $1^{\text {st }}$ relapsed patients; NR, non-remission; MDS, RA/RCMD/RAEB, myelodysplastic syndrome, refractory anemia/refractory cytopenia with multilineage dysplasia/refractory anemia with excess blast; BM, bone marrow; PBSC, peripheral blood stem cell; TBI, total body irradiation; BU-CTX, busulfan-cyclophosphamide; CTX-ATG, cyclophosphamide-antithymocyte globulin; CsA, cyclosporin A; GVHD, graft versus host disease; SOS, sinusoidal obstruction syndrome; MTC, major transplant-related complication

*'Other leukemia' refers to biphenotypic leukemia and adult T-cell leukemia.

rentially expressed or excreted polypeptides and proteins, have the potential to improve the early and accurate diagnosis of allo-HSCT-related complications without the need for invasive procedures such as biopsy (Reddy and Ferrara, 2003; Schulenburg et al., 2004). Recently, several studies have demonstrated the usefulness of proteomic approaches in the identification of marker peptide patterns for graft-versus-host disease (GVHD) and other allo-HSCT-related complications (Kaiser et al., 2004; Srinivasan et al., 2006; Weissinger et al., 2006, 2007). The identification of specific patterns that are modulated during disease progression or therapy would enhance current methods of diagnosis and follow-up care (Weissinger et al., 2006).

In general, all patients receive chemotherapy or irradiation prior to allo-HSCT, as a means to suppress immune reactions and help eradicate the disease prior to the infusion of hematopoietic stem cells (HSCs). However, this process may lead to undesirable tissue damage, triggering the release of inflammatory cytokines and promoting hemostatic alterations. Sinusoidal obstruction syndrome (SOS) is one of the most common early complications of HSCT, leading to significant morbidity and mortality. This disease appears to stem from endothelial damage to the sinusoids and small 
A

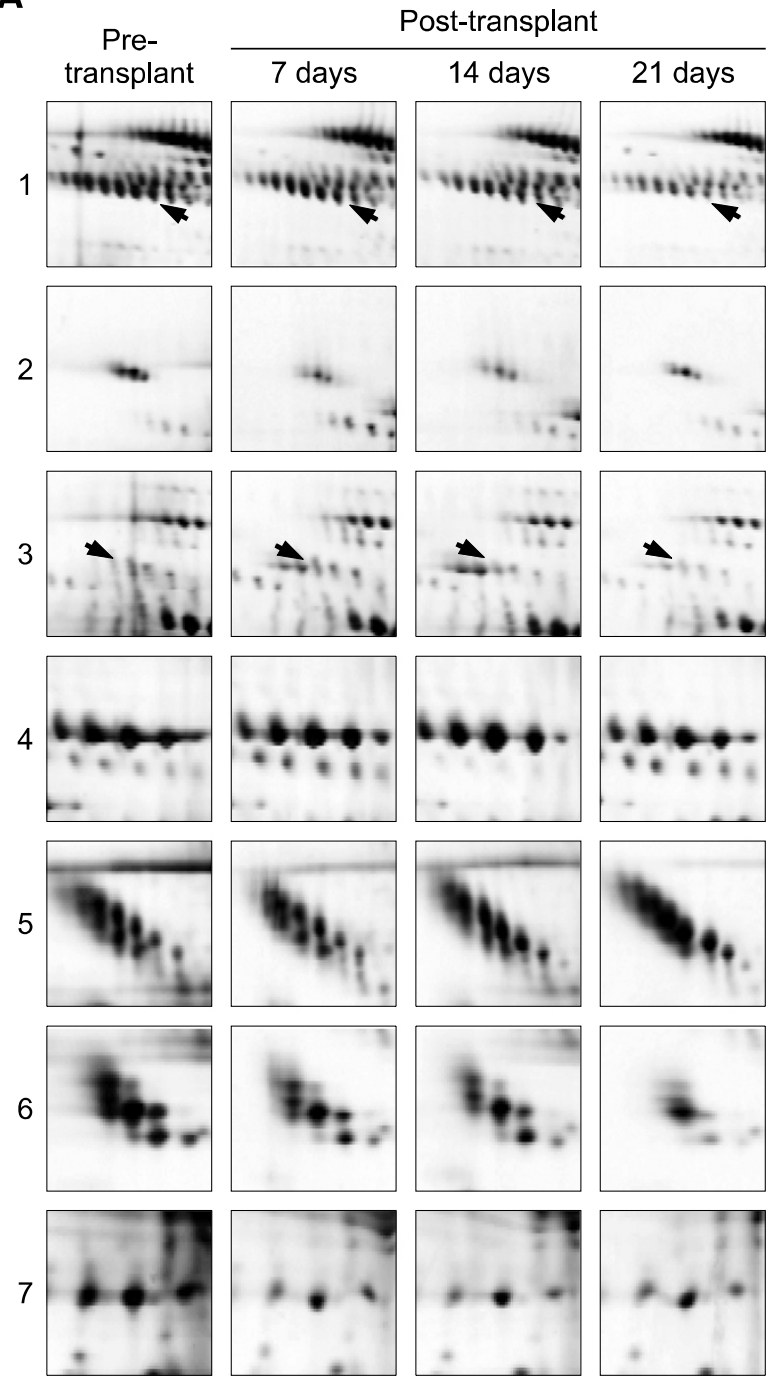

B
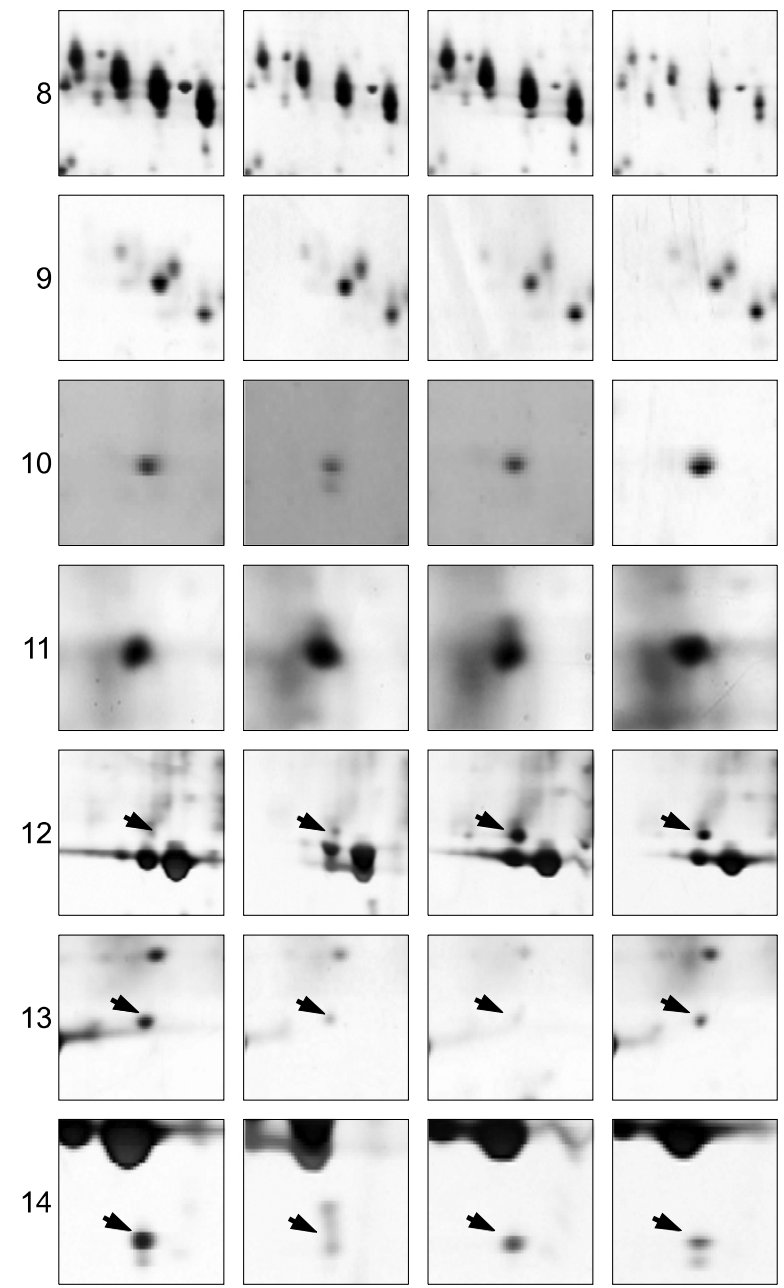

Figure 1. The analyses of human sera via 2-DE. Enlargement of the 2-DE gel spots identified by LC-MS/MS.

hepatic venules in response to conditioning regimens. Subclinical clotting and alterations in fibrinolytic profiles have occurred in patients receiving HSCT (Notoya et al., 1998), and fibrinolytic and clotting parameters are predictive of SOS after HSCT (Tanikawa et al., 2000; Villalon et al., 2000; Sartori et al., 2005). Acute GVHD also is one of the major early complications after HSCT, manifesting as SOS, wherein host tissues are perceived as antigenically foreign and are attacked by $T$ cells in the graft. Proinflammatory cytokines are overproduced in response to total body irradiation (TBI) and/or high-dose chemotherapy, which directly or indirectly facilitates T-cell activation by upregulating the level of adhesion and costimulation molecules on antigen-presenting cells (Schultz and Arnold, 1990). Patient serum protein profiles undergo changes during the development of acute GVHD after HSCT. Weissinger and colleagues reported the usefulness of proteomic screening in the early detection of acute GVHD occurring after allo-HSCT (Weissinger et al., 2006, 2007). In addition, several proteins present in the body fluid of patients undergo changes in response to allo-HSCT. Severe infection and other complications of HSCT also influence protein profiles.

In this study, we conducted proteomic analyses to identify proteins that were differentially expressed in response to allo-HSCT. Among such proteins, the expression of $\mathrm{C}$-reactive protein (CRP) and haptoglobin were significantly altered in response to transplantation. 
Table 2. Fourteen proteins identified in five patients.

\begin{tabular}{|c|c|c|c|c|c|c|c|c|}
\hline $\begin{array}{l}\text { Spot } \\
\text { No. }\end{array}$ & $\begin{array}{c}\text { Accession } \\
\text { No. }\end{array}$ & $\begin{array}{l}\text { Identified } \\
\text { proteins }\end{array}$ & $\begin{array}{c}\text { Seq. } \\
\text { Cov. }(\%)\end{array}$ & $\begin{array}{l}\text { Matched } \\
\text { peptide }\end{array}$ & $\mathrm{pl}$ & $\begin{array}{l}\mathrm{MW} \\
(\mathrm{kDa})\end{array}$ & $\begin{array}{l}\text { PLGS } \\
\text { score }\end{array}$ & $\begin{array}{c}\text { Mascot } \\
\text { score }\end{array}$ \\
\hline 1 & IPI00017601 & $\mathrm{CP}$ & $6.8(10)^{*}$ & $5(8)^{*}$ & 5.4 & 122.9 & 630 & 319 \\
\hline 2 & IPI00017696 & C1s & $6.4(5)$ & $3(3)$ & 4.8 & 78.1 & 278 & 115 \\
\hline 3 & IPI00019568 & Prothrombin & 8.1 (13) & $4(7)$ & 5.6 & 71.4 & 265 & 147 \\
\hline 4 & IPI00019591 & CFB & $10.6(8)$ & $7(12)$ & 6.8 & 143.1 & 517 & 140 \\
\hline 5 & IPI00550991 & SERPINA3 & $29.9(30)$ & $13(15)$ & 5.4 & 50.7 & 1931 & 483 \\
\hline 6 & IPI00022431 & AHSG & - (8) & - (3) & 5.8 & 47.5 & - & 93 \\
\hline 7 & IPI00021891 & FGG & $15.4(14)$ & $7(14)$ & 5.3 & 52.1 & 762 & 241 \\
\hline 8 & IPI00431645 & Haptoglobin & $25.9(42)$ & $8(23)$ & 8.4 & 31.6 & 746 & 643 \\
\hline 9 & IPI00291262 & APOJ & $16.9(15)$ & $5(5)$ & 5.8 & 53.0 & 244 & 165 \\
\hline 10 & IPI00021841 & APOE & $28.3(30)$ & $7(12)$ & 5.6 & 36.2 & 631 & 434 \\
\hline 11 & IPI00022391 & APCS & $27.3(34)$ & $9(14)$ & 6.1 & 25.4 & 686 & 424 \\
\hline 12 & IPI00022381 & CRP & $13.8(16)$ & $3(4)$ & 5.4 & 25.1 & 201 & 74 \\
\hline 13 & IPI00021841 & APOA1 & $62.1(64)$ & $16(70)$ & 5.5 & 30.7 & 1583 & 914 \\
\hline 14 & IPI00022423 & PRBP & $9.9(23)$ & $2(5)$ & 5.7 & 23.3 & 284 & 70 \\
\hline
\end{tabular}

CP, Ceruloplasmin; C1s, Complement C1s subcomponent; CFB, Complement factor B; SERPINA3, $\alpha 1$-antichymotrypsin; AHSG, $\alpha 2$-HS-glycoprotein; FGG, Fibrinogen $\gamma$ chain; APOJ, Apolipoprotein J; APOE, Apolipoprotein E; APCS, Serum amyloid P; CRP, C-reactive protein; APOA1, Apolipoprotein A1; PRBP, plasma retinol-binding protein

${ }^{*}$ Numbers in parentheses were sequenced and mapped data using the MASCOT DAEMON program.

\section{Results}

\section{Clinical characteristics of patients after allo-HSCT}

Venous blood samples were obtained from five representative patients who underwent allo-HSCT, and examined by proteome analysis. The five patients were diagnosed with AML (data not shown). The differentially expressed proteins identified in 2-DE analysis were validated using sera from 78 additional patients who underwent allo-HSCT at CNUH between June 2002 and April 2008. The majority of the patients $(n=66)$ received transplants for hematologic malignancy [i.e., 33 patients with $A M L, 18$ with acute lymphocytic leukemia (ALL), 5 with chronic myeloid leukemia (CML), 5 with myelodysplastic syndrome (MDS), 3 with non-Hodgkin lymphoma (NHL), 1 with acute biphenotypic leukemia, and 1 with adult $\mathrm{T}$ cell leukemia], whereas 12 patients received transplants because of hematopoietic failure syndrome [i.e., 11 patients with aplastic anemia (AA) and 1 with hemophagocytic lymphohistiocytosis (HLH)]. The characteristics of these patients are summarized in Table 1.

\section{Differentially expressed proteins in serum after allo-HSCT}

To investigate proteins that were differentially expressed in patient serum during allo-HSCT, serum proteins were enriched via the depletion of albumin and IgG. Proteins from whole and depleted sera separated by 2-DE (data not shown). Protein profiles between pre- and post-transplantation were compared using the Progenesis Samespots program V2.0, and significant changes were visualized. 14 spots were examined using LC-MS/MS, and most proteins were identified as acute phase proteins (APPs) (Figure 1, Table 2). Comparison of the protein level before and after transplantation revealed three distinct patterns. Level of serum amyloid P, APOE, and CRP were higher 14 days or 21 days after allo-HSCT than before transplantation. However, concentrations of

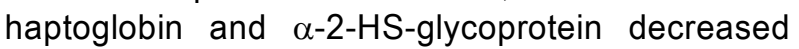
after transplantation. Level of $\mathrm{C} 1 \mathrm{~s}, \alpha 1$-anti-chymotrypsin, prothrombin, complement factor $\mathrm{B}$, fibrinogen $\gamma$ chain, ceruloplasmin, PRBP, APOA1, and APOJ were modulated in irregular patterns. These results demonstrated that the level of some APPs was changed in response to transplantation and may therefore serve as potential markers for the diagnosis or evaluation of patients who receive allo-HSCT.

\section{Validation of CRP and haptoglobin level in 78 patients after allo-HSCT}

To further validate the differentially expressed proteins found in 5 patients, additional 78 patients who underwent allo-HSCT were analyzed. Changes of CRP and haptoglobin level within initial group of 5 patients showed more consistent pattern than other spots. Thus serum level of CRP and haptoglobin were measured on a weekly basis before 
Table 3. Clinical characteristics of patients with or without MTC.

\begin{tabular}{|c|c|c|c|}
\hline Characteristics & MTC $(+)(n=22)$ & MTC $(-)(n=56)$ & $P$ value \\
\hline Patient age, median range (years) & $33.6(17-51)$ & $38.7(16-62)$ & $0.428^{b}$ \\
\hline Patient age, $<40$ or $\geq 40$ & $16 / 6(72.7 / 27.3)$ & $26 / 30(46.4 / 53.6)$ & $0.036^{d}$ \\
\hline $\operatorname{Sex}(M / F)$ & $11 / 11$ & $29 / 27$ & $0.829^{d}$ \\
\hline Time to ANC > 500/ $\mu \mathrm{l}$, median range (days) & $14.0(9-40)$ & $8.3(9-19)$ & $0.757^{\mathrm{C}}$ \\
\hline Time to platelet $>20,000 / \mu \mathrm{l}$, median range (days) & $23.2(8-89)$ & $7.1(7-89)$ & $0.031^{\mathrm{c}}$ \\
\hline Time to platelet $>50,000 / \mu \mathrm{l}$, median range (days) & $32.4(12-148)$ & $19.47(7-42)$ & $0.087^{\mathrm{C}}$ \\
\hline Underlying disease & & & $0.541^{d}$ \\
\hline AML/ALL/Other leukemia & $9 / 6 / 0$ & $24 / 12 / 2$ & \\
\hline $\mathrm{CML} / \mathrm{MDS} / \mathrm{AA} / \mathrm{NHL} / \mathrm{HLH}$ & $3 / 2 / 2 / 0 / 0$ & $2 / 3 / 9 / 3 / 1$ & \\
\hline Disease status at $\mathrm{HSCT}^{\mathrm{a}}$ & $17 / 5$ & $48 / 8$ & $0.500^{c}$ \\
\hline Graft type, sibling/untreated & $12 / 10$ & $42 / 14$ & $0.078^{d}$ \\
\hline Stem cell source, BM/PBSC & $7 / 15$ & $21 / 35$ & $0.638^{d}$ \\
\hline Sex compatibility, match/mismatch/missing & 13/9/- & $39 / 19 / 1$ & $0.600^{d}$ \\
\hline ABO compatibility, match/mismatch/data missing & $8 / 13 / 1$ & 28/27/1 & $0.317^{d}$ \\
\hline Conditioning regimen & & & $0.276^{d}$ \\
\hline Fludarabine-based & 11 & 36 & \\
\hline CTX-TBI & 8 & 9 & \\
\hline BU-CTX & 1 & 3 & \\
\hline CTX-ATG & 2 & 8 & \\
\hline GVHD prophylaxis & & & $0.277^{d}$ \\
\hline CsA-based & 13 & 41 & \\
\hline Tacrolimus-based & 8 & 14 & \\
\hline Data missing & 1 & 1 & \\
\hline
\end{tabular}

CTX-TBI, cyclophosphamide-total body irradiation; BU-CTX, busulfan-cyclophosphamide.

${ }^{a}$ Either acute leukemia in first remission or MDS; RA/RCMD or CML; CP, aplastic anemia or HLH; compared with acute leukemia in second remission/non-remission or MDS; RAEB or CML; AP/BC or non-Hodgkin's lymphoma, ${ }^{b}$ Student's T test, ${ }^{c}$ Mann-Whitney, ${ }^{d}$ Chi-square test, ${ }^{e}$ Fisher's exact test.

and after allo-HSCT. Based on a previously used definition (Glucksberg et al., 1974; Shulman et al., 1980; Przepiorka et al., 1995), the observed transplant-related complications in an MTC-positive group (i.e., $\geq$ grade $\|$ aGVHD, SOS) and an MTC-negative group (i.e., FUO, $\geq$ grade II mucositis, hemorrhagic cystitis, grade I aGVHD) were further categorized. Of the 22 patients who developed MTC, 4 (18.1\%) experienced fatal outcomes within 100 days after allo-HSCT. Relapse after allo-HSCT occurred in 24 patients (30.8\%), with 13 $(54.1 \%)$ experiencing a relapse within 100 days.

When MTC-positive and -negative groups were considered separately, the median overall CRP level were showed a characteristic monophasic pattern that varied with time and were significantly higher on days 14 and 21 in the MTC-positive group [i.e., when these data are expressed as medians $(25 \%, 75 \%)$, the values were $3.60(1.70$, $9.60)$ and $1.70(0.65,3.10)$, respectively, on day 14 $(P=0.004) ; 1.05(0.40,3.90)$ and $0.50(0.20,0.80)$, respectively, on day $21(P=0.013)$ ] (data not shown). Mean haptoglobin level showed decreasing pattern during the period of observation by proteomic analysis. When remission and relapse groups were observed separately, the level were significantly high on day 14 in the relapsed group than in the remission group (i.e., mean \pm SD values of $114.4 \pm 78.9$ and $65.6 \pm 58.2$, respectively; $P=0.027$ ), but were not correlated with MTC concentrations (data not shown).

To establish potential risk factors for the development of MTC, association of variables suspected to influence the development of complications after allo-HSCT were examined to the MTC-positive and -negative groups (Table 3). There were no significant differences in age, gender, underlying disease, transplant type, stem cell source, conditioning regimen, GVHD prophylaxis, ABO incompatibility, or time (days) from allo-HSCT to an absolute neutrophil count $>500 / \mu l$. However, the MTC-positive group required more time than did the MTC-negative group to achieve a platelet count greater than $20,000 / \mu l$ after allo-HSCT $(P=$ 0.031 ). Also, age differences (age $<40 \mathrm{yr}$ versus $\geq 40 \mathrm{yr}$ ) were significantly increased the risk factor for the occurrence of MTC $(P=0.036)$. More patients younger than $40 \mathrm{yr}$ were included in the MTC-positive group $(72.7 \%$ in the MTC-positive group and $46.4 \%$ in the MTC-negative group). Time (days) from allo-HSCT to have a platelet count $>50,000 / \mu \mathrm{l}$ and patients group underwent 
Table 4. Correlation between serum CRP and haptoglobin level and the development of complications or relapse after allo-HSCT.

\begin{tabular}{llc}
\hline & & $P$ value \\
\hline Acute GVHD ( $\geq$ Grade II) & Maximal CRP level & $<0.001^{\mathrm{a}}$ \\
& Maximal Haptoglobin level & $0.810^{\mathrm{b}}$ \\
& CRP level on day 14* & $0.010^{\mathrm{a}}$ \\
Sinusoidal obstruction syndrome & CRP level on day 21* & $0.030^{\mathrm{a}}$ \\
& Maximal CRP level & $0.004^{\mathrm{a}}$ \\
& Maximal Haptoglobin level & $0.840^{\mathrm{b}}$ \\
& CRP level on day 7* $7^{*}$ & $0.019^{\mathrm{a}}$ \\
Other acute complications & CRP level on day 14* & $0.003^{\mathrm{a}}$ \\
& CRP level on day 21* & $0.018^{\mathrm{a}}$ \\
& Maximal CRP level & $0.002^{\mathrm{a}}$ \\
& Maximal Haptoglobin level & $0.602^{\mathrm{b}}$ \\
& CRP level on pre-transplant & $0.005^{\mathrm{a}}$ \\
Relapse after HSCT & CRP level on day 7 & $<0.001^{\mathrm{a}}$ \\
& CRP level on day 14* & $<0.001^{\mathrm{a}}$ \\
& CRP level on day 21* & $0.001^{\mathrm{a}}$ \\
& Haptoglobin level on pre-transplant & $0.036^{\mathrm{b}}$ \\
\hline
\end{tabular}

${ }^{a}$ Mann-Whitney test, ${ }^{b}$ Student's T test.

${ }^{*}$ Once a week after transplant.

allo-HSCT from unrelated donor were related to the occurrence of MTC without statistical significance $(P=0.087, P=0.078$, respectively).

It also analyzed according to the correlation between representative APPs and complications after HSCT (Table 4). The maximal CRP level in each patients were showed significant effects to the development of complications during further courses of allo-HSCT, including acute GVHD $(P<$ $0.001)$, SOS $(P=0.004)$ and other acute complications such as FUO $(P=0.002)$. And also, when these data were analyzed according to the median CRP level for each time points, the occurrence of MTC was significantly affected to the median CRP level on days 14 and 21. Overall, maximal haptoglobin level were not significantly associated with other acute complications $(P=0.602)$; however, maximal pre-transplant haptoglobin level were associated with the development of other acute complications $(P=0.036)$.

Consequently, univariate and multivariate analyses of factors that might potentially increase the risk of MTC were performed (Table 5). Our results showed that MTC was significantly associated with young age (i.e., less than $40 \mathrm{yr}$ old) and maximal CRP level $(P=0.049$ and $P<0.001$, respectively). CRP level on days 14 and 21 were also risk factors for MTC. When these data were analyzed according to maximal CRP level, the risk of MTC increased more than 6.9-fold in patients with CRP level $\geq 20 \mathrm{mg} / \mathrm{dl}$ than in patients with
CRP level $<10 \mathrm{mg} / \mathrm{dl}$. Multivariate analysis of the same factors revealed that young age (i.e., less than $40 \mathrm{yr}$ old) and CRP level on day 21 were the strongest independent variables $(P=0.017$ and 0.032 , respectively). Relapse is a major problem in patients undergoing allo-HSCT. When the level of CRP and haptoglobin in patients with relapse after allo-HSCT was compared, there were no significant differences with regards to pre-transplant variables and the timing of engraftment. However, maximal haptoglobin level were correlated to relapse after allo-HSCT $(P=0.042)$ and mean haptoglobin level on day 14 were significantly higher in relapsed patients $(P=0.027)$ (Table 4). This relationship was not found when the maximal and median CRP level at each time points were analyzed (data not shown). Univariate analysis of relapse risk after allo-HSCT revealed that maximal haptoglobin level, disease status at the time of transplantation, and mean haptoglobin level on day 14 were risk factors for relapse $(P=0.019, P=$ 0.005 , and $P=0.030$, respectively). When these data were analyzed according to maximal haptoglobin level, the risk of relapse increased more than 12.7-fold in patients with haptoglobin level $\geq$ $200 \mathrm{mg} / \mathrm{dl}$ compared to patients with haptoglobin level $<150 \mathrm{mg} / \mathrm{dl}$. Multivariate analysis of the same factors revealed that disease status was the strongest independent variable $(P=0.003)$ (Table $5)$.

These results indicate that the expression 
Table 5. Univariate and multivariate analyses of factors influencing the risk of MTC and relapse after allo-HSCT.

\begin{tabular}{|c|c|c|c|c|}
\hline \multirow{2}{*}{ Risk factor } & \multicolumn{2}{|c|}{ Univariate analysis } & \multicolumn{2}{|c|}{ Multivariate analysis } \\
\hline & $\mathrm{RR}(95 \%, \mathrm{Cl})$ & $P$ value ${ }^{a}$ & $\mathrm{RR}(95 \%, \mathrm{Cl})$ & $P$ value $^{a}$ \\
\hline Age group ( $<40$ or $\geq 40$ ) & $2.557(1.006,6.601)$ & 0.049 & $3.651(1.256,10.626)$ & 0.017 \\
\hline Maximal CRP level & $1.099(1.051,1.149)$ & $<0.001$ & & \\
\hline CRP level on day 14 & $1.080(1.031,1.131)$ & 0.001 & & \\
\hline CRP level on day 21 & $1.091(1.012,1.177)$ & 0.023 & & 0.032 \\
\hline Category of maximal CRP & & 0.001 & & \\
\hline$<10$ & 1 & & & \\
\hline$\geq 10$ and $<20$ & $3.175(1.170,8.618)$ & 0.023 & & \\
\hline$\geq 20$ & $6.867(2.328,20.254)$ & $<0.001$ & & \\
\hline Disease status ${ }^{b}$ & $3.591(1.466,8.794)$ & 0.005 & $4.168(1.626,10.684)$ & 0.003 \\
\hline Maximal haptoglobin level & $1.006(1.001,1.011)$ & 0.019 & & \\
\hline haptoglobin level on day 14 & $1.006(1.001,1.011)$ & 0.030 & & \\
\hline Category of maximal haptoglobin & & 0.006 & & \\
\hline$<150$ & 1 & & & \\
\hline$\geq 150$ and $<200$ & $1.696(0.693,4.152)$ & 0.247 & & \\
\hline$\geq 200$ & $12.675(2.657,60.467)$ & 0.001 & & \\
\hline
\end{tabular}

$\mathrm{RR}$, relative risk; $\mathrm{Cl}$, confidence interval.

${ }^{a}$ Cox proportional regression analysis, ${ }^{b}$ Either acute leukemia in first remission or MDS; RA/RCMD or CML; CP, aplastic anemia or HLH; compared with acute leukemia in second remission/non-remission or MDS; RAEB or CML; AP/BC or non-Hodgkin's lymphoma.

patterns of CRP and haptoglobin are significantly associated with the development of MTC and the risk of relapse after allo-HSCT, and suggest that monitoring of changes in CRP and haptoglobin level after allo-HSCT would allow for the identification of patients at risk for early transplant-related complications and relapse.

\section{Discussion}

When patients experience bone marrow failure or hematological malignancy, treatment generally involves chemotherapy or radiotherapy followed by the transplantation of a new and functional immune system. Although allo-HSCT has dramatically improved patient survival rate, the broader applications of this therapy remain limited because of the life-threatening complications that often occur after therapy, such as severe infection and acute GVHD (Horowitz et al., 1990; Gratwohl et al., 2002). Early diagnosis and better control of these complications would increase the safety of allo-HSCT, particularly with respect to the broad applications of the procedure. Because of the complexity of most problems that occur after allo-HSCT, knowledge of the behavior of single molecules and potential posttranslational modifications may not be sufficient to gain useful insight into the development of these conditions. However the generation of specific proteome patterns that are modulated during disease progression or therapy would likely prove useful in the diagnosis and follow-up of patients who experience complications after allo-HSCT. Proteomic analyses have emerged as a technology capable of deciphering biological processes and discovering biomarkers present in tissues and bodily fluids. Previous studies strongly suggest that proteomic analyses of body fluids will become increasingly important in the clinical diagnosis of various diseases (Osin et al., 1998; Voss et al., 2001). Recent proteomic data have focused on hematologic malignancies such as AML (Cho et al., 2004; Kwak et al., 2004) and the follow-up care of patients after allo-HSCT (Kaiser et al., 2004; Srinivasan et al., 2006; Weissinger et al., 2006, 2007).

In this study, 14 proteins, including CRP and haptoglobin, identified during allo-HSCT by 2-DE and LC-MS/MS are classified as APPs, a group of proteins whose plasma concentrations increase (i.e., positive acute phase proteins) or decrease (i.e., negative acute phase proteins) in response to inflammation. Generally, haptoglobin, CRP, C1s, prothrombin, fibrinogen $\gamma$ chain, $\alpha 1$-anti-chymotrypsin, complement factor $B$, serum amyloid $P$, and ceruloplasmin are positive APPs, whereas PRBP is considered a negative APP. Apart from the listed proteins, changes in APOE, APOJ, and APOA1 level were observed. Differentially expressed proteins, including APPs were involved in fibrinolytic processes and clotting parameters and changes in the expression level of these proteins may thus also be expected during the period 
following allo-HSCT.

In the further validation of CRP and haptoglobin level in 78 patients after allo-HSCT, maximal CRP level influenced the development of acute complications, including acute GVHD, SOS, and FUO, after further courses of allo-HSCT. In particular, CRP level on days 14 and 21 was associated with the occurrence of MTC. The CRP level at each time points was closely associated with occurrence of other acute complications. In addition, the CRP level on day 21 was found to be an independent risk factor for MTC. Although young age (i.e., less than $40 \mathrm{yr}$ old) was the strongest predictive factor, our results may have been influenced by the fact that more young subjects were included in the MTC-positive group than in the MTC-negative group. CRP is an acute phase protein that is produced by the liver and is a reliable marker of systemic inflammation. The protein is induced in liver cells by IL-6 (Schultz and Arnold, 1990), which is produced by many types of cells such as monocytes, macrophages, fibroblasts, and endothelial cells. These cells are likely to survive the conditioning regimen and respond to the tissue damage caused by high-dose cytotoxic agents and infections. CRP and its role in the development of MTC after allo-HSCT were reported in the previous studies (Schots et al., $1998,2002,2003)$. It is said that early increase in serum level of CRP is independent risk factor for the occurrence of MTC. As these studies, our results suggest that not only the severity and multiplicity of precipitating causes, but also individual inflammatory response level, determine outcome during the 3 weeks after allo-HSCT. In addition, a correlation between CRP and leukemic relapse was found, wherein mean CRP level throughout the early post-SCT episode were significantly lower in relapsing patients than in others (Min et al., 2006). Also, GVHD was significantly associated with relapse. These studies have suggested that the procurement of inflammatory status, as reflected by higher serum CRP level, allows antigen-activated donor $\mathrm{T}$ cells to maintain their anti-leukemic effects, whereas the suppression of proinflammatory cytokines might interfere with the graft-versus-leukemia (GVL) phenomenon. However, we found no correlation between CRP level and leukemic relapse. Mean haptoglobin level during allo-HSCT exhibited a monophasic pattern, as did median CRP concentrations. However, maximal haptoglobin level and haptoglobin level at each time points were not associated with the development of MTC. Only haptoglobin concentrations prior to transplantation were correlated with other acute complications such as FUO. Also, maximal haptoglobin level and haptoglobin level at day 14 emerged as risk factors for relapse after allo-HSCT in patients with disease at the time of transplantation. Haptoglobin is a positive acute-phase protein produced by liver cells (Arredouani et al., 2003). Hepatic expression of haptoglobin is strongly induced by inflammatory mediators such as IL-6-type cytokines (Wang et al., 2001). In addition to a role as a hemoglobin scavenger, haptoglobin has been shown to behave as an angiogenic (Cid et al., 1993), antioxidant (Arredouani et al., 2003), and anti-inflammatory factor (Langlois and Delanghe, 1996; Arredouani et al., 2003). Haptoglobin and its variants are potent immunosuppressors of lymphocyte function (Arredouani et al., 2003; Huntoon et al., 2008), and also several studies have indicated that the protein may be useful as a cancer biomarker (Ahmed et al., 2004; Bharti et al., 2004; Ang et al., 2006; Okuyama et al., 2006; Sandoval et al., 2007). Despite extensive research on haptoglobin, no studies have yet examined the correlation between haptoglobin and complications after allo-HSCT.

Overall, these results demonstrate that if CRP level are elevated during the third week after transplantation, clinicians should recognize the probability of MTC and seek clinical evidence suggestive of this condition. Although any correlation between relapse and CRP level did not show, maximal level of haptoglobin was associated with relapse after allo-HSCT. Haptoglobin is a positive APP like CRP; however, the proteins differ in clinical significance. The underlying pathophysiological mechanism remains unclear, and also our studies have some limitations as these data come from heterogeneous patient group, conditioned with different regimens and transplanted with differing cell sources, but the identification of a new biomarker able to predict relapse after allo-HSCT may be of considerable interest. Finally, we suggest that monitoring the expression of CRP and haptoglobin after allo-HSCT will allow for identification of patients who are at risk of early transplant-related complications and relapse.

\section{Methods}

\section{Patients}

Venous blood samples were obtained prior to allo-HSCT and weekly after allo-HSCT. The serum was separated and stored at $-80^{\circ} \mathrm{C}$ until further use. The study protocol was approved by the Ethics Committee of Chonnam National University Hwasun Hospital (CNUH). Subjects were fully informed and written consent was obtained from each participant. 


\section{Conditioning and transplantation}

Forty-seven patients were treated with a fludarabine-containing regimen. Of these, 32 patients received fludarabine (30 mg/m $/$ day for 6 days) and busulfan $(0.8 \mathrm{mg} / \mathrm{kg}$ every 6 $\mathrm{h}$ for 4 days). In addition, Campath ${ }^{\circledR}$ (alemtuzumab) was added to the fludarabine and busulfan regimens of 15 patients who underwent unrelated allo-HSCT. Standard-intensity protocols were used to treat 21 patients. Of these, 17 patients received TBI $(6 \times 2$ Gy over 3 days $)$ and cyclophosphamide (60 mg/kg for 2 days), and 4 patients received busulfan ( $4 \mathrm{mg} / \mathrm{kg}$ for 4 days) followed by cyclophosphamide (120 mg/kg for an additional 2 days). Ten patients received cyclophosphamide $(50 \mathrm{mg} / \mathrm{kg}$ for 4 days) and ATG (Thymoglobuline) ( $2.5 \mathrm{mg} / \mathrm{kg}$ for 3 days).

A total of 54 patients received stem cells from HLA-identical family donors, and 24 patients received transplants from unrelated donors [i.e., 18 patients received transplants from a matched unrelated donor (MUD) and 6 patients received transplants from a mismatched donor).

Stem cells were derived from peripheral blood stem cells in 50 patients and bone marrow in 28 patients. As prophylactic treatment against GVHD, 54 patients were treated with methotrexate (MTX) or mycophenolate mofetil (MMF) and cyclosporin A (CsA), and 22 patients were treated with Prograf ${ }^{\mathbb{R}}$ (tacrolimus, FK506) with or without methotrexate (MTX). The remaining two patients were treated with cyclosporin A (CsA) alone. All patients received standard supportive care, including empirical broad-spectrum antibiotic therapy in case of fever, low-dose continuous infusions of heparin (100 U/kg daily) to prevent SOS, and high-dose immunoglobulins and acyclovir to prevent herpes simplex/CMV. Platelet transfusions were given when platelet counts decreased to less than $20 \times 10^{9}$ platelets/L. Granulocyte colony stimulating factor was administered to all patients until the achievement of stable neutrophil recovery, defined by an absolute neutrophil count (ANC) $>1.0 \times 10^{9} / \mathrm{L}$.

\section{Definition of engraftment and major complications}

Engraftment was estimated by the time required to obtain an ANC of 500 or more and the maintenance of a platelet count of 20,000 to 50,000 for 3 days, without the need for a platelet transfusion. Bone marrow aspiration and section biopsies were performed on day 21 after stem cell infusion. In addition, we checked for the presence of a short tandem repeat (STR) after HSCT and compared patients with donor STR, and performed FISH analysis of sex chromosomes in sex-mismatched transplant patients. Acute GVHD was graded on a four-point scale [i.e., ranging from mild disease (I) to severe disease (IV)] (Glucksberg et al., 1974; Przepiorka et al., 1995) and chronic GVHD was classified as either limited or extensive, as previously described (Shulman et al., 1980; Atkinson et al., 1989). Fever of unknown origin (FUO) was defined by a body temperature $\geq 38.3^{\circ} \mathrm{C}$ for at least 2 consecutive days. SOS was diagnosed according to the presence of hyperbilirubinemia ( $>3.0 \mathrm{mg} / \mathrm{dl}$ ), weight gain ( $>2.5 \%$ of initial weight), and right upper quadrant pain, with or without the presence of hepatomegaly (McDonald et al., 1984). Hematological and non-hematological toxicity were measured and graded according to the criteria described by the National Cancer Institute-Common Toxicity Criteria (NCl-CTC) version 3.0.

\section{Depleted serum sample preparation}

The two major protein components of human serum (i.e., albumin and $\mathrm{lgG}$ ) were depleted via immunoaffinity with albumin and IgG depletion kit according to the manufacture's protocol (Sigma).

\section{Two-dimensional gel electrophoresis}

Two-dimensional gel electrophoresis (2-DE) was performed using isoelectric focusing (IEF) and SDS-PAGE analysis. Dry-strips were rehydrated with $200 \mu \mathrm{g}$ of protein in solubilization solution (9 $\mathrm{M}$ urea; $2 \%$ CHAPS; $4 \mathrm{M}$ thiourea; $2 \%$ IPG buffer, $\mathrm{pH} 4$ to $7 ; 18 \mathrm{mM}$ DTT and a trace of bromophenol blue) and loaded onto Immobiline Drystrips. Rehydration proceeded for $12 \mathrm{~h}$ at room temperature and IEF was conducted at $20^{\circ} \mathrm{C}$ in gradient mode for 1 minute at $200 \mathrm{~V}, 90 \mathrm{~min}$ at $3,500 \mathrm{~V}$ and $10 \mathrm{~h}$ at $3,500 \mathrm{~V}$. Following IEF separation, the dry-strips were equilibrated for 30 minutes in an equilibration buffer $(50 \mathrm{mM}$ Tris- $\mathrm{HCl} \mathrm{pH} 6.8$, $6 \mathrm{M}$ urea, $30 \%$ glycerol, $2 \%$ SDS and a trace of bromophenol blue). We then added $0.25 \%$ DTT to the first equilibration buffer, and replaced DTT with $4.5 \%$ iodoacetamide in the second equilibration buffer. The second dimension of the separation was carried out on a SDS polyacrylamide vertical slab gel. After 2-DE, proteins were visualized by silver staining according to the manufacture's protocol (GE Healthcare).

\section{Image analysis}

The 2-DE images were analyzed using the Progenesis SameSpots program, V2.0. (Nonlinear Dynamics, Nonlinear, Inc) (Mattacks et al., 2003).

\section{Destaining and in-gel trypsin digestion of protein and extraction}

Protein spots separated by 2-DE were excised manually from 2-DE gels and destained using oxidation buffer (15 $\mathrm{mM}$ potassium ferricyanide and $50 \mathrm{mM}$ sodium thiosulphate). Destained gels were re-swelled and dehydrated using $100 \mu \mathrm{l}$ of $100 \mathrm{mM}$ ammonium bicarbonate in $50 \%$ acetonitrile. The gels were re-swollen and dehydrated for an additional two to three times, then dried. The dried gels were digested by $50 \mathrm{mM}$ ammonium bicarbonate, $\mathrm{pH} 8$, containing $0.05 \mu \mathrm{g} / \mu \mathrm{l}$ trypsin for 16 hours at $37^{\circ} \mathrm{C}$. The tryptic peptides were extracted three times to recover all of the peptides from the gel particles. The recovered peptides were concentrated by drying the final volume of the extracts in a vacuum centrifuge. The concentrated peptides were then mixed with $20 \mu \mathrm{l}$ of $0.1 \%$ formic acid in $3 \%$ acetonitrile in preparation for liquid chromatography tandem mass spectrometry (LC-MS/MS) analysis.

\section{LC-MS/MS analysis and database searches}

Nano LC of tryptic peptides was performed using a Waters 
Nano LC system equipped with a Waters C18 nano column. Samples were loaded onto the column. Peptides were eluted from the column with a gradient ranging from $2 \%$ to $40 \%$ binary solvent B1 for $30 \mathrm{~min}$ at $0.4 \mu \mathrm{l} / \mathrm{min}$. Mass spectrometry analysis of tryptic peptides was performed using a Waters Synapt ${ }^{\mathrm{TM}}$ HDMS. The mass spectrometer was operated in V-mode for all measurements. All analyses were performed using a positive mode Nano ESI with a NanoSpray source. Accurate mass LCMS data were collected via an alternating [i.e., low energy (MS) and elevated energy $\left(\mathrm{MS}^{\mathrm{E}}\right)$ ] mode or Data Dependent Acquisition (DDA) mode of acquisition. Continuum LC-MS/MS data were processed and used in database searches using the Protein Lynx Global Server (PLGS), version 2.3 (Waters). Ion detection, clustering and normalization were performed using PLGS. Processed data were used to search the IPI human database (Liu et al., 2004; Wang et al., 2005). Processed ions were sequenced and mapped against the IPI human database using the PLGS and MASCOT DAEMON programs (http://www.matrixscience. com).

\section{Measurement of CRP and haptoglobin level}

Level of CRP were measured using an Hitachi 7600-110 automated biochemical analyzer (Hitachi High Technologies., Tokyo, Japan) and turbidimetric immunoassays (TIA), with a reference range of $0 \mathrm{mg} / \mathrm{dl}$ to $0.5 \mathrm{mg} / \mathrm{dl}$. Haptoglobin level were determined via immunoturbidometry using a commercial HAPT kit (Roche, Switzerland) and the COBAS Integra 800 biochemical analyzer (Roche, Switzerland), with a reference range of approximately 30 $\mathrm{mg} / \mathrm{dl}$ to $200 \mathrm{mg} / \mathrm{dl}$.

\section{Statistical analysis}

Student's $t$ tests were performed to test for differences in the means of continuous measurements and these results were confirmed using the Mann-Whitney test. The association between categorical variables was investigated using the Chi square or Fisher's exact tests. Factors of interest were compared between patient groups. Preliminary univariate analyses were performed to identify factors that could be used to build a Cox proportional hazard regression model. This model was then used to determine the probability of major transplant-related complications and relapse.

\section{Acknowledgements}

This research was supported by a grant of the Korea Healthcare technology R\&D Project, Ministry for Health, Welfare \& Family Affairs, Republic of Korea (A080489) and the Happy tech. program through the National Research Foundation of Korea (NRF) funded by the Ministry of Education, Science and Technology (2010-0020765).

\section{References}

Ahmed N, Barker G, Oliva KT, Hoffmann P, Riley C, Reeve S, Smith Al, Kemp BE, Quinn MA, Rice GE. Proteomic-based identification of haptoglobin-1 precursor as a novel circulating biomarker of ovarian cancer. $\mathrm{Br} \mathrm{J}$ Cancer 2004; 91:129-40

Ang IL, Poon TC, Lai PB, Chan AT, Ngai SM, Hui AY, Johnson PJ, Sung JJ. Study of serum haptoglobin and its glycoforms in the diagnosis of hepatocellular carcinoma: a glycoproteomic approach. J Proteome Res 2006;5:2691-700

Arredouani M, Matthijs P, Van Hoeyveld E, Kasran A, Baumann H, Ceuppens JL, Stevens E. Haptoglobin directly affects T cells and suppresses T helper cell type 2 cytokine release. Immunology 2003;108:144-51

Atkinson K, Horowitz MM, Gale RP, Lee MB, Rimm AA, Bortin $M M$. Consensus among bone marrow transplanters for diagnosis, grading and treatment of chronic graft-versus-host disease. Committee of the International Bone Marrow Transplant Registry. Bone Marrow Transplant 1989;4: 247-54

Bharti A, Ma PC, Maulik G, Singh R, Khan E, Skarin AT, Salgia R. Haptoglobin alpha-subunit and hepatocyte growth factor can potentially serve as serum tumor biomarkers in small cell lung cancer. Anticancer Res 2004;24:1031-8

Cho JW, Kim JJ, Park SG, Lee DH, Lee SC, Kim HJ, Park BC, Cho $\mathrm{S}$. Identification of B-cell translocation gene 1 as a biomarker for monitoring the remission of acute myeloid leukemia. Proteomics 2004;4:3456-63

Cid MC, Grant DS, Hoffman GS, Auerbach R, Fauci AS, Kleinman HK. Identification of haptoglobin as an angiogenic factor in sera from patients with systemic vasculitis. J Clin Invest 1993;91:977-85

Copelan EA. Hematopoietic stem-cell transplantation. N Engl J Med 2006;354:1813-26

Glucksberg H, Storb R, Fefer A, Buckner CD, Neiman PE, Clift RA, Lerner KG, Thomas ED. Clinical manifestations of graft-versus-host disease in human recipients of marrow from HL-A-matched sibling donors. Transplantation 1974; 18:295-304

Gratwohl A, Brand R, Apperley J, Biezen Av A, Bandini G, Devergie A, Schattenberg A, Frassoni F, Guglielmi C, lacobelli S, Michallet M, Kolb HJ, Ruutu T, Niederwieser D. Graft-versus-host disease and outcome in HLA-identical sibling transplantations for chronic myeloid leukemia. Blood 2002;100:3877-86

Horowitz MM, Gale RP, Sondel PM, Goldman JM, Kersey J, Kolb HJ, Rimm AA, Ringden O, Rozman C, Speck B, et al. Graft-versus-leukemia reactions after bone marrow transplantation. Blood 1990;75:555-62

Huntoon KM, Wang Y, Eppolito CA, Barbour KW, Berger FG, Shrikant PA, Baumann $H$. The acute phase protein haptoglobin regulates host immunity. J Leukoc Biol 2008; 84:170-81

Kaiser T, Kamal H, Rank A, Kolb HJ, Holler E, Ganser A, Hertenstein B, Mischak $\mathrm{H}$, Weissinger EM. Proteomics applied to the clinical follow-up of patients after allogeneic hematopoietic stem cell transplantation. Blood 2004;104: 340-9

Kwak JY, Ma TZ, Yoo MJ, Choi BH, Kim HG, Kim SR, Yim CY, 
Kwak YG. The comparative analysis of serum proteomes for the discovery of biomarkers for acute myeloid leukemia. Exp Hematol 2004;32:836-42

Langlois MR, Delanghe JR. Biological and clinical significance of haptoglobin polymorphism in humans. Clin Chem 1996;42:1589-600

Mattacks CA, Sadler D, Pond CM. The cellular structure and lipid/protein composition of adipose tissue surrounding chronically stimulated lymph nodes in rats. J Anat 2003; 202:551-61

McDonald GB, Sharma P, Matthews DE, Shulman HM, Thomas ED. Venocclusive disease of the liver after bone marrow transplantation: diagnosis, incidence, and predisposing factors. Hepatology 1984;4:116-22

Min CK, Kim SY, Eom KS, Kim YJ, Kim HJ, Lee S, Kim DW, Lee JW, Min WS, Kim CC. Patterns of C-reactive protein release following allogeneic stem cell transplantation are correlated with leukemic relapse. Bone Marrow Transplant 2006;37:493-8

Notoya A, Sawada K, leko M, Tarumi T, Koizumi K, Fukada Y, Sato N, Yasukouchi T, Koike T. Subclinical alterations in coagulation and fibrinolysis in patients undergoing autologous peripheral blood stem cell transplantation. Leuk Lymphoma 1998;28:405-13

Okuyama N, Ide Y, Nakano M, Nakagawa T, Yamanaka K, Moriwaki K, Murata K, Ohigashi H, Yokoyama S, Eguchi H, Ishikawa O, Ito T, Kato M, Kasahara A, Kawano S, Gu J, Taniguchi N, Miyoshi E. Fucosylated haptoglobin is a novel marker for pancreatic cancer: a detailed analysis of the oligosaccharide structure and a possible mechanism for fucosylation. Int J Cancer 2006;118:2803-8

Osin P, Shipley J, Lu YJ, Crook T, Gusterson BA Experimental pathology and breast cancer genetics: new technologies. Recent Results Cancer Res 1998;152:35-48

Przepiorka D, Weisdorf D, Martin P, Klingemann HG, Beatty P, Hows J, Thomas ED. 1994 Consensus Conference on Acute GVHD Grading. Bone Marrow Transplant 1995; 15:825-8

Reddy P, Ferrara JL. Immunobiology of acute graft-versushost disease. Blood Rev 2003;17:187-94

Sandoval JA, Turner KE, Hoelz DJ, Rescorla FJ, Hickey RJ, Malkas LH. Serum protein profiling to identify high-risk neuroblastoma: preclinical relevance of blood-based biomarkers. J Surg Res 2007;142:268-74

Sartori MT, Spiezia L, Cesaro S, Messina C, Paris M, Pillon M, Saggiorato G, Pagnan A, Girolami A, Zanesco L, Cella G. Role of fibrinolytic and clotting parameters in the diagnosis of liver veno-occlusive disease after hematopoietic stem cell transplantation in a pediatric population. Thromb Haemost 2005;93:682-9

Schots R, Kaufman L, Van Riet I, Lacor P, Trullemans F, De Waele M, Van Camp B. Monitoring of C-reactive protein after allogeneic bone marrow transplantation identifies patients at risk of severe transplant-related complications and mortality. Bone Marrow Transplant 1998;22:79-85

Schots R, Van Riet I, Othman TB, Trullemans F, De Waele
M, Van Camp BM, Kaufman L. An early increase in serum levels of C-reactive protein is an independent risk factor for the occurrence of major complications and 100-day transplant-related mortality after allogeneic bone marrow transplantation. Bone Marrow Transplant 2002;30:441-6

Schots R, Kaufman L, Van Riet I, Ben Othman T, De Waele M, Van Camp B, Demanet C. Proinflammatory cytokines and their role in the development of major transplant-related complications in the early phase after allogeneic bone marrow transplantation. Leukemia 2003;17:1150-6

Schulenburg A, Turetschek K, Wrba F, Vogelsang H, Greinix HT, Keil F, Mitterbauer M, Kalhs P. Early and late gastrointestinal complications after myeloablative and nonmyeloablative allogeneic stem cell transplantation. Ann Hematol 2004;83:101-6

Schultz DR, Arnold PI. Properties of four acute phase proteins: C-reactive protein, serum amyloid A protein, alpha 1 -acid glycoprotein, and fibrinogen. Semin Arthritis Rheum 1990;20:129-47

Shulman HM, Sullivan KM, Weiden PL, McDonald GB, Striker GE, Sale GE, Hackman R, Tsoi MS, Storb R, Thomas ED. Chronic graft-versus-host syndrome in man. A long-term clinicopathologic study of 20 Seattle patients. Am J Med 1980;69:204-17

Srinivasan R, Daniels J, Fusaro V, Lundqvist A, Killian JK, Geho D, Quezado M, Kleiner D, Rucker S, Espina V, Whiteley G, Liotta L, Petricoin E, Pittaluga S, Hitt B, Barrett AJ, Rosenblatt K, Childs RW. Accurate diagnosis of acute graft-versus-host disease using serum proteomic pattern analysis. Exp Hematol 2006;34:796-801

Tanikawa S, Mori S, Ohhashi K, Akiyama H, Sasaki T, Kaku H, Hiruma K, Matsunaga T, Morita T, Sakamaki H. Predictive markers for hepatic veno-occlusive disease after hematopoietic stem cell transplantation in adults: a prospective single center study. Bone Marrow Transplant 2000;26: 881-6

Villalon L, Avello AG, Cesar J, Odriozola J, Lopez J, Oteyza JP, Larana JG, Cantalapiedra A, Navarro JL. Is veno-occlusive disease a specific syndrome or the exacerbation of physiopathologic hemostatic changes in hematopoietic stem cell transplantation (HSCT)? Thromb Res 2000;99:439-46

Voss $\mathrm{T}$, Ahorn $\mathrm{H}$, Haberl P, Dohner $\mathrm{H}$, Wilgenbus $\mathrm{K}$. Correlation of clinical data with proteomics profiles in 24 patients with B-cell chronic lymphocytic leukemia. Int J Cancer 2001;91:180-6

Wang $Y$, Kinzie E, Berger FG, Lim SK, Baumann H. Haptoglobin, an inflammation-inducible plasma protein. Redox Rep 2001;6:379-85

Weissinger EM, Mischak H, Ganser A, Hertenstein B. Value of proteomics applied to the follow-up in stem cell transplantation. Ann Hematol 2006;85:205-11

Weissinger EM, Schiffer E, Hertenstein B, Ferrara JL, Holler E, Stadler M, Kolb HJ, Zander A, Zurbig P, Kellmann M, Ganser A. Proteomic patterns predict acute graft-versushost disease after allogeneic hematopoietic stem cell transplantation. Blood 2007;109:5511-9 